\title{
Educação ambiental: o papel das mulheres na preservação do ambiente
}

A presente pesquisa tem como objetivo discutir sobre o papel das mulheres na preservação do ambiente demonstrando o vínculo em que ela desenvolve com a natureza. Neste sentido, o trabalho confirma algumas informações importantes na relação entre mulher e natureza, direitos que garantam a inclusão do gênero em várias questões sociais, culturais e ambientais. Podemos apontar, entretanto, que a relação de proximidade com o tema ambiental, a mulher está, na maioria das vezes, longe do processo de tomada de decisão em relação às políticas ambientais. Sendo assim, este artigo permite uma melhor compreensão das relações que as mulheres estabelecem com a natureza, no material, social e cultural, o que mostra a importância do seu papel na preservação do ambiente.

Palavras-chave: Educação Ambiental; Meio Ambiente; Sustentabilidade.

\section{Environmental education: the role of women in preserving the environment}

\begin{abstract}
The present research aims to discuss the role of women in preserving the environment by demonstrating the link in which it develops with nature. In this sense, the work confirms some important information on the relationship between women and nature, rights that guarantee the inclusion of gender in various social, cultural and environmental issues. We can, however, point out that the relation of proximity to the environmental theme, women are, for the most part, far from the decision-making process in relation to environmental policies. Thus, this article allows a better understanding of the relationships that women establish with nature, in material, social and cultural, which shows the importance of their role in preserving the environment.
\end{abstract}

Keywords: Environmental Education; Environment; Sustainability.

Topic: Planejamento, Gestão e Políticas Públicas Ambientais

Reviewed anonymously in the process of blind peer.

Valdilene Monteiro Rosa

Faculdade Guaraí, Brasil

valmonteirorosa@gmail.com

Katiúcia Freitas Sousa

Faculdade Guaraí, Brasil

annykati0304@hotmail.com

Nívia Alves Sales Szulczewski

Faculdade Guaraí, Brasil

http://lattes.cnpq.br/8161747696826496

nivia.sales@faculdadeguarai.com.br
Received: 07/02/2016

Approved: 14/08/2016

\author{
Aluísio Vasconcelos de Carvalho \\ Faculdade Guaraí, Brasil \\ http://lattes.cnpq.br/5200758055263996 \\ aluisiovasconcelos@gmail.com
}

Referencing this:

ROSA, V. M.; SOUSA, K. F.; SZULCZEWSKI, N. A. S.; CARVALHO, A. V.. Educação ambiental: o papel das mulheres na preservação do ambiente. Natural Resources, v.6, n.1, p.18-26, 2016. DOI: http://doi.org/10.6008/SPC2237-9290.2016.001.0002 


\section{INTRODUÇÃO}

A Lei 9.795/99 ressalta a educação ambiental como os processos por meio dos quais o indivíduo e a coletividade constroem valores sociais, conhecimentos, habilidades, atitudes e competências voltadas para a conservação do meio ambiente, para que todos possam ter uma qualidade de vida digna e saudável (ADAMS, 2013).

O conceito de Meio Ambiente, Desenvolvimento Sustentável e Gênero geram alguns debates na sociedade. A importância de compreender as relações em que mulheres e homens estabelecem com o ambiente e o vínculo que cada um deles desenvolve com a natureza, demonstra o papel importante de ambos no processo de mudança da sociedade, o qual varia segundo a raça, etnia, geração e o sexo em diferentes cenários, classe social e econômica (HERNÁNDEZ, 2010).

Segundo Cunha (2015), o Brasil teve uma evolução no sentido da construção de uma institucionalidade voltada à promoção dos direitos das mulheres e à desigualdade de gênero, pode-se mencionar a criação da Secretaria de Políticas para as Mulheres pela Presidência da República (SPM-PR) em 2003, durante o governo Luís Inácio Lula da Silva.

No entanto, um dos maiores desafios enfrentados, está relacionado à remoção das barreiras para o crescimento da participação das mulheres no mercado de trabalho. Mesmo que hoje 53,9\% da população economicamente ativa seja feminina (IBGE, 2012), sabemos que a desigualdade salarial entre homens e mulheres é gritante, e que a participação em lideranças e cargos políticos ainda é um tabu para a sociedade. Cunha (2015) afirma que todos os seres humanos nascem livres e iguais em dignidade e direitos.

Entende-se que esta realidade afeta as mulheres, para que haja mudança nesse cenário é necessário o compromisso com a questão da desigualdade de gênero. Torreão (2007), explica que o termo gênero designa a elaboração cultural do feminino e masculino, em que a subordinação da mulher em relação ao homem se circunscreve a uma interpretação cultural dominada por uma relação social e de poder entre ambos.

O desenvolvimento sustentável é um tema contemporâneo, muito discutido nas políticas e programas ambientais. Em suas entrelaças vemos surgir enunciações que integram o gênero como ferramenta fundamental para o alcance dessa meta, e possivelmente a melhoria dos problemas socioambientais.

Diante disso, pode-se notar a importância da mulher para a melhoria dos recursos naturais, a gestão do meio ambiente e a redução da pobreza, nos levando a reflexão sobre o efeito que ela tem na sustentabilidade e como suas ações influenciam nosso futuro (ÁVILA et al, 2016).

O papel da mulher desde a antiguidade, tem sido rotulado pelo homem como uma dona de casa, mãe do lar, que cuida de seus filhos enquanto o marido traz o sustento para casa. Devido a essa divisão, por muito tempo a mulher não fez parte de alguns problemas ambientais ao qual ela é peça fundamental dentro da sociedade para a conservação e preservação de seu ambiente. 
Sendo assim, o objetivo desta pesquisa é de analisar e refletir a importância da mulher para a preservação do meio ambiente e observar que a sustentabilidade só pode acontecer com a colaboração e a ajuda de todos.

\section{METODOLOGIA}

O presente estudo utiliza como método a revisão bibliográfica, o qual tem como finalidade reunir e resumir o conhecimento científico já produzido sobre o tema investigado, ou seja, permite buscar, avaliar e sintetizar as evidências disponíveis para contribuir com o desenvolvimento do conhecimento na temática, sendo que a metodologia abordada neste projeto é a pesquisa bibliográfica exploratória.

De acordo com Xavier et al, (2009), a pesquisa é a busca do conhecimento a partir de várias fontes, analisadas sob diferentes aspectos, tanto para aprender como para ampliar o conhecimento. Segundo Gil (2008), a pesquisa exploratória tem como objetivo proporcionar maior familiaridade com o problema, com vistas a torná-lo mais explícito. Pode envolver levantamento bibliográfico, entrevistas com pessoas experientes no problema pesquisado.

Para a elaboração da presente revisão integrativa as seguintes etapas foram percorridas: a) para guiar a pesquisa, formulou-se a seguinte questão: Os problemas socioambientais podem ter influência da desigualdade de gênero? b) realizou-se em agosto de 2016 a busca das publicações indexadas nas seguintes bases de dados: Base da CAPES, Library Online (Scielo) e Gloogle Acadêmico.

\section{DISCUSSÃO TEÓRICA}

\section{Ações que Permeiam os Direitos Femininos}

A preocupação com os problemas ecológicos e ambientais aumenta diariamente. Os feministas vêm propondo discussões sobre o reflexo da degradação do meio ambiente, e a relação com as mulheres (DUARTE, 2015).

A relação mulher e natureza são antigas, ao longo da história da humanidade, a simbologia está muito presente nas reflexões que instituem no feminino uma proximidade com a natureza, tornando sua relação íntima, e de suma importância para o futuro do meio ambiente. Entretanto, o que se percebe no cotidiano, ainda de forma muito rudimentar, e que apesar da proximidade com o tema meio ambiente, a mulher está ainda muito distante dos processos de tomada de decisão em relação às políticas ambientais (JACOBI et al., 2015).

A relação da mulher com a natureza não tem sido somente nos dias de hoje, vê-se que desde a antiguidade existiam deusas onde a história faz um eixo articulador entre natureza e mulher. A própria história mostra a mulher como um ser mitológico, como uma Deusa (mãe da natureza, mãe da terra, Deusa do amor) e isso traz um caráter feminista e naturalista, pois faz um paralelo da mulher com a natureza (GARCIA, 2009). 
Os Vikings e Celtas viam a figura feminina como mulheres inteligentes, poderosas guerreiras e de grande sabedoria, ligavam-nas com a natureza, inclusive na antiguidade descobriam os ciclos e mudanças na natureza através do seu corpo e seu ciclo menstrual, marcando assim o tempo entre a mudança tanto em relação as plantas quanto ao clima da natureza (ANGELIN, 2006).

As mulheres estão vivendo uma era de uma economia de subsistência, são grandes vítimas desta crise ambiental que atinge o mundo e as pessoas em sua máxima potencialidade. Desde a antiguidade, sempre houve uma divisão de classes e de gênero, vê-se que mesmo em uma era digital e moderna, a mulher continua por fora de muitos assuntos atuais devido a discriminação social. A mulher é vista como uma imagem de fragilidade, dona do lar, mas aos poucos tem conquistado seu espaço, sendo participativa nos problemas ambientais do mundo de acordo com as necessidades coletivas e individuais dentro de seu espaço de vivência (ANGELIN, 2006; TORREÃO, 2007).

Hernández (2010), ressalta que foi apenas no ano de 1970, que ouve uma preocupação significante com as condições das necessidades básicas, a produtividade rural e as atividades no setor informal, o autor afirma que é através de capacitações que ocorra o acesso ao desenvolvimento econômico e sustentabilidade.

Torreão (2007), menciona que ao adotar a igualdade de gênero como análise nas políticas públicas, demonstra-se a importância que se deve atribuir às questões reivindicadas pelas mulheres, enquanto um fator estratégico para o alcance do desenvolvimento do meio ambiente e sustentabilidade.

Em 1974, Françoise d'Eaubonne adotou pela primeira vez o termo eco feminismo para destacar o potencial que as mulheres têm para encabeçarem uma revolução ecológica que estabelecerá novas relações entre os gêneros, entre todos os seres humanos e com a natureza (GARCIA, 2009).

De acordo com Castro e Abramovay (2005), a importância do enfoque de gênero está centrada na vivência e na incorporação de ações de homens e mulheres nas políticas e programas. Neste sentido, uma política com essa visão indicaria com mais especificidade, o uso diferenciado dos recursos que estabelecem tanto homens quanto mulheres entre si. Não se trata de inserir, somente, as mulheres no processo de desenvolvimento por meio de programas assistencialistas e projetos de conservação que reproduzem seu "papel tradicional" e aumentam a tripla jornada de trabalho.

O ecofeminismo propõe a mulher o direito de lutar por suas necessidades, dentro de uma sociedade cheia de tabus, o direito de ir e vir, o direito a saúde, educação, moradia e outros. A mulher tem conquistado seus direitos e tem mostrado a sua importância dentro deste cenário no qual antes ela era excluída (JUNCADELLA, 1994).

Sherry Ortner (1979), foi a primeira feminista a desbravar a suposta proximidade das mulheres com a natureza. Sua obra destaca que as mulheres tradicionalmente estão associadas com "algo" detentor de status inferior, que todas as culturas subvalorizam: a própria natureza. A associação colocaria a mulher/natureza em oposição ao homem, identificado com a cultura e, logicamente, com o ambiente construído. 
Vemos que mesmo mediante a divisão entre a classe masculina e feminina, a mulher tem cada vez mais assumido seu lugar e também responsabilidades, e muitas vezes têm superado até mesmo ao trabalho do homem.

Cunha (2015), relata que através desse cenário, órgãos governamentais e organizações nacionais e internacionais passaram a trabalhar o tema através de políticas públicas criando leis, tendo compromissos e objetivos, em busca de mudanças significativas. Ainda, segundo o mesmo autor, para essas ações acontecerem e serem realmente eficazes, é necessário promover um forte senso de propósito comum e de compromisso entre governos, empresas, investidores, cidadãos, consumidores, trabalhadores e educadores, a fim de que essa realidade, que leva a uma estatística gritante de desigualdade de gênero, tenha efeito na sociedade.

Torreão (2007), também acredita que é através de conferências e congressos criados para as mulheres que essa realidade pode ser modificada, a Agenda 21 de Ação das Mulheres, defende: direitos reprodutivos, combate à violência sexual e doméstica e reconhecimento pela carga do trabalho domiciliar. As Lâminas de Avaliação Comunitária das Mulheres: desenvolve os sistemas políticos, as prioridades sociais e o desenvolvimento humano. A ação da Paz e Direitos Humanos; buscam a Globalização e Sustentabilidade, o Acesso e Controle dos Recursos; a Segurança Ambiental e Saúde, que também, são questões a serem debatidas para o sucesso da igualdade de gênero no Brasil.

\section{O Papel da Mulher no Desenvolvimento Sustentável}

O tratamento da temática ambiental é uma atividade bastante complexa, tanto do ponto de vista prático, quanto do ponto de vista teórico, sendo então necessário ser discutida nos debates as questões de política, conservação do ambiente natural e a preservação da vida no planeta (BACINELLO \& CARVALHO, 2013).

Na Agenda 21 emergem compromissos e princípios orientadores de consensos, a necessidade de se efetivarem mudanças, e de garantir o pleno exercício dos direitos humanos e a inclusão das mulheres em todas as dimensões, tendo em vista promoção à igualdade de gênero e a inserção da sustentabilidade como foco primordial. Assim, a presença feminina é percebida socialmente como indispensável. Percebe-se então, a necessidade uma necessária valorização da mulher e sua afinidade com o ambiente e natureza, e ao tão sonhado desenvolvimento sustentável (CARNEIRO \& SCHIMANSKI, 2009).

De acordo com os dados do Instituto Brasileiro de Geografia e Estatística (IBGE, 2012), pouco mais da metade da população brasileira é feminina e está economicamente ativa no Brasil. Todavia são números que correspondem aos empregos formais e não formais. Os maiores índices de escolaridade e de empregos formais foram percebidos na zona urbana, enquanto para as mulheres da zona rural, essa realidade de trabalho formal ainda é uma esperança, devido à cultura da mulher da zona rural ser mais forte na agricultura familiar e no cuidado da família (MANFRINATE \& SATO, 2015).

Acredita-se que essas transformações e realidade não serão automáticas, mas sim, construídas socialmente, sendo uma tarefa coletiva na conquista e no reconhecimento de direitos e da cidadania. 
Nascimento (2013) afirma que a questão gênero está diretamente relacionada ao meio ambiente e consequentemente ao desenvolvimento sustentável, ambas necessitam ser trabalhadas em conjunto.

Contudo, a mulher tem um papel fundamental na redução dos padrões insustentáveis de consumo, produção e também estimulação de investimentos em atividades produtivas ambientalmente saudáveis e sustentáveis. Sendo assim, os estudos e debates sobre os direitos da mulher são importantes, colocando-se em primeira instância, buscando fazer valer seus direitos adquiridos até o presente momento.

Hernández (2010), explica que as mulheres, através de suas atividades cotidianas, estão mais perto da natureza que os homens, em vários sentidos, sendo eles espirituais e conceituais. A intimidade da mulher com a natureza torna os processos biológicos de reprodução determinante com princípio feminino, que coloca a relação das mulheres com a natureza em uma postura necessariamente conservacionista e geradora da vida.

De modo geral a mulher tem mostrado ter talento, quanto ao que diz respeito a ser sustentável, tem demonstrado amor e respeito por uma vida de qualidade, esforçando-se para preservar os recursos naturais que a natureza oferece, um exemplo disso são as mulheres de hoje que se dedicam a agricultura e também a pescaria, muitas vezes elas têm sido as grandes provedoras e responsáveis pelo sustento de sua própria família. Desta forma, é possível dizer que a mulher tem feito sua identidade numa sociedade machista, mostrando que a mulher é tão capaz quanto o homem (ANGELIN, 2006).

Torreão (2007), afirma que para a inclusão das mulheres nas atividades produtivas, é necessário apresentar seu posicionamento na sociedade, conhecer e fazer valer seus direitos. Essa mudança influiu para modificação social de valores e principalmente dos papéis a elas atribuídos.

Segundo Jacobi et al, (2015), o papel da mulher na sociedade ocorre de forma multifacetada, não só nas práticas que garantem a reprodução da vida social no espaço doméstico, mas também no espaço público, exercendo papel fundamental na conservação e preservação do ambiente e na vida social.

A Plataforma 20, um sistema criado na Rio+20, reflete as expectativas, consensos e esforços de um grupo de mulheres brasileiras com diversos perfis de atuação, que integram a Rede Brasileira de Mulheres Líderes pela Sustentabilidade, as quais acreditam em um futuro mais justo e igualitário para todos (BRASIL, 2012).

Atualmente, as mulheres vêm ganhando espaço em direitos sociais, econômicos em acesso à saúde, à educação, melhores salários e maior participação no poder público e na política. Outro documento importante, a carta da terra, tem como princípios, proteger e restaurar a integridade dos sistemas ecológicos da Terra, em especial a preocupação com a diversidade biológica e pelos processos naturais que sustentam a vida, adotando planos para desenvolvimento sustentável, trabalhando também com a conservação e a reabilitação do meio ambiente. Ela também visa a participação ativa das mulheres em todos os aspectos da vida econômica, política, civil, social e cultural (HOSHI, 2012).

Garcia e Yunes (2015), afirmam que é através de graves situações e dos riscos socioambientais vivenciados pelas famílias, é que se nota a importância da educação no contexto familiar para a formação da consciência ambiental e do desenvolvimento humano. Segundo os mesmos autores, a educação ambiental 
visa uma reflexão e uma ação crítica em que todos os cidadãos se expressem aos problemas ambientais. Sendo assim, percebe-se a importância da compreensão do ser humano para o tema ambiental.

\section{O Desafio do Desenvolvimento Sustentável: um Problema de Todos}

O desenvolvimento sustentável surgiu no final da década de 80, como um paradigma para dar direção às nações, em benefício do progresso da qualidade de vida da população, sem danificar as próximas gerações, o que significa que a dimensão econômica e social do desenvolvimento provoca a objetivação ecológica da conservação dos recursos hídricos, na conservação da biodiversidade e preservação do meio ambiente (VIANA, 2004).

Sachs (2004), enfatiza que o crescimento mesmo que acelerado, não é sinônimo de desenvolvimento se ele não reduz a pobreza e se não atenua as desigualdades sociais. É preciso que se evite a armadilha da competitividade espúria e, em última instância, autodestrutiva, com base na depreciação da força de trabalho e dos recursos naturais. E este é o desafio do nosso tempo: criar comunidades sustentáveis que possibilitem a emergência de experimentos de modelos de desenvolvimento econômico mais integrados às realidades regionais e compromissados com a preservação ambiental. Busca-se garantir ambientes sociais e culturais onde todos possam satisfazer as necessidades e aspirações sem diminuir e/ou comprometer o usufruto destes bens às gerações futuras.

Jacobi (2006) ressalta que o tema da sustentabilidade implica na necessidade da multiplicação de práticas sociais pautadas pela ampliação do direito à informação e de educação ambiental numa perspectiva integradora. Trata-se de potencializar iniciativas a partir do suposto que maior acesso à informação e transparência na gestão dos problemas ambientais urbanos podem implicar uma reorganização de poder e autoridade.

Sabe-se que vivemos em um mundo globalizado, isto se apresenta como uma necessidade a ser enfrentada por todos, principalmente na questão do meio ambiente sustentável. O princípio da dignidade humana, dentre elas, cabe respeitar à ecologia e a sustentabilidade, deste modo se torna dever e direito de todos, das presentes e futuras gerações, a preocupação e a responsabilidade do meio ambiente sadio e equilibrado (RICHTER \& VERONESE, 2014).

De acordo com Pereira e Curi (2012), o desenvolvimento sustentável visa à garantia do meio ambiente ecologicamente equilibrado para uma melhor qualidade de vida, é fundamental para o homem a manutenção, e também ações, atitudes conscientes e coerentes, que conseguirá alcançar o bem-estar e o equilíbrio do meio ambiente. Podemos então, afirmar que uma sociedade é tanto mais sustentável quanto maior for a sua organização, com tudo garantindo o bem-estar da população e dos ecossistemas na qual está inserida (FAUSTINO \& AMADOR, 2016).

\section{CONSIDERAÇÕES FINAIS}

Nesta pesquisa percebeu-se a importância da mulher no campo ambiental e a relação que as entrelaçam. A educação ambiental, enquanto processo permanente de formação de cidadãos críticos e 
participativos, ainda tem a necessidade de um olhar transformador, para que a igualdade de gênero seja um aliado da preservação do meio ambiente.

Sabe-se que as mulheres em seu trabalho do dia a dia ficam mais interligadas com a natureza, e que exercem função fundamental para a proteção do ambiente e sustentabilidade. Da mesma maneira, os homens também exercem um papel árduo na agricultura familiar, responsável pelo exercício de atividades mais pesadas, o que resulta na união de ambos os gêneros para que aja alcance da sustentabilidade do planeta.

A educação ambiental e gênero estão de uma forma ou de outros entrelaçados e ambos dependendo um do outro. Nota-se que é através de ações, movimentos femininos, congresso e conferências, que essa realidade pode tomar um rumo diferente, no qual a mulher assume o seu papel de peça fundamental na transformação e preservação do meio ambiente.

Neste sentido, ao se considerar a interação gênero-ambiente nos programas de ação é necessário destacar a vinculação entre os ecossistemas e a população, levando em conta os diferentes elementos da estrutura social que determinam a relação com o meio ambiente, o contexto espacial e temporal destas relações, e a interação de processos globais e locais no que diz respeito à questão ambiental.

\section{REFERÊNCIAS}

ADAMS, B. G. A importância da Lei 9.795/99 e das diretrizes curriculares nacionais da Educação Ambiental para docentes. Revista Monografias Ambientais, v.10, n.10, p.2148-2157, 2013.

AGENDA 21. Conferência das Nações Unidas sobre meio ambiente e desenvolvimento. Brasília: Senado Federal, 1997.

ANGELIM, R.. Gênero e meio ambiente: atualidade do ecofeminismo. Revista Espaço Acadêmico, v.5, n.58, 2006.

ÁVILA, D. A; RIBEIRO, P. R. C.; HENNING, P. C.. O gênero é fundamental para o desenvolvimento sustentável: reflexões sobre a operação de dispositivos em programas globais e seus efeitos para a Educação Ambiental. Revista Eletrônica do Mestrado de Educação Ambiental, p.95-119, 2016.

BACINELLO, E.; CARVALHO, O. M.. Análise Socioambiental e Relações de Gênero: um estudo na hidrelétrica de Santo Antônio/Rondônia. Gênero na Amazônia, Belém, n.4, 2013.

BRASIL. Ministerio do Meio Ambiente. Plataforma 20: Rede de Mulheres

Brasileiras Líderes pela sustentabilidade. Brasília: 2016.

CASTRO, M. G.; ABRAMOVAY, M.. Gênero e meio ambiente. Cortez, 2005.

CUNHA, T. G.. Igualdade de gênero no ambiente corporativo: desafios, avanços e tendências para grandes empresas com atuação no Brasil. Dissertação (Mestrado em História, Política e Bens Culturais) - Centro de Pesquisa e Documentação de História Contemporânea do Brasil, 2015.
DUARTE, R. C. P.. O eco feminismo e a luta pela igualdade de gênero: uma análise à luz da teoria bidimensional de justiça. Dissertação (Mestrado em Direito) - Universidade de Caxias do Sul, 2015.

FAUSTINO, M; AMADOR, F.. O conceito de "sustentabilidade": migração e mudanças de significados no âmbito educativo. Indagatio Didactica, v.8, n.1, 2016.

GARCIA, L.. A Relação Mulher e Natureza: laços e nós enredados na teia da vida. Gaia Scientia, v.3, n.1, p.11-16, 2009.

GARCIA, N. M; YUNES, M. A. M.. Educação familiar como proposta de investigação e intervenção em educação ambiental. Revista Eletrônica do Mestrado de Educação Ambiental, p.105-120, 2015.

GIL, A. C.. Métodos e técnicas da pesquisa social. 6 ed. São Paulo: Atlas, 2008.

HERNÁNDEZ, C. O.. Gênero e Meio Ambiente: A construção do discurso para o Desenvolvimento Sustentável. Ambiente y Desarrollo, v.14, n.26, p.3-33, 2010.

HOSHI, S. S. C.. A carta da terra e o princípio da integridade ecológica. Veredas do Direito: Direito Ambiental e Desenvolvimento Sustentável, v.9, n.17, p.31, 2012.

IBGE. Instituto Brasileiro de Geografia e Estatística. Pesquisa Mensal de Emprego, 2012.

JACOBI, P.. Cidade e Meio Ambiente: percepções e práticas em São Paulo. 2 ed. São Paulo: Annablume, 2006. 
JACOBI, P. R; EMPINOTTI, V.; TOLEDO, R. F.. Gênero e meio ambiente. Ambiente \& Sociedade, v.18, n.1, 2015.

JUNCADELLA, I. L.. Ecofeminismo o Feminismo ecologista. Madri: 1994.

MANFRINATE, R; SATO, M.. O Trabalho das mulheres Pantaneiras e a Avaliação Ecossistêmica do Milleniun: uma ressignificação por meio da Educação Ambiental. Revista Eletrônica do Mestrado de Educação Ambiental, v.32, n.1, p.270-289, 2015.

NASCIMENTO, E. M. D.. Meio ambiente e sustentabilidade. Seminário Internacional Fazendo Gênero, 10. Anais. Florianópolis, 2013.

ORTNER, B.. Está a mulher para o homem assim como a natureza para a cultura? In: ROSALDO, M.; LAMPHERE, L.. A mulher, a cultura e a sociedade. Rio de Janeiro: Paz e Terra, 1979. p.95-120

PEREIRA, S. S.; CURI, R. C. Meio Ambiente Impacto Ambiental e Desenvolvimento sustentável. Revista de Administração, Contabilidade e Sustentabilidade, v.2, n.4, p.35-57, 2012.
CARNEIRO, K. M.; SCHIMANSKI, E. Algumas considerações sobre o papel da mulher. In: ENCONTRO PARANAENSE DE PESQUISA E EXTENSÃO EM CIÊNCIAS SOCIAIS APLICADAS, 5. Anais. Cascavel, 2009.

RICHTER, D; VERONESE, J. R. P.. O direito da criança e o direito ambiental: o compromisso com a sustentabilidade das presentes e futuras gerações por meio da construção de uma cultura fraterna. In: SEMINÁRIO INTERNACIONAL DE DEMANDAS SOCIAIS E POLÍTICAS PÚBLICAS NA SOCIEDADE CONTEMPORÂNEA, 11. Anais. 2014.

TORREÃO, N.. A liderança feminina no desenvolvimento sustentável. Revista Ártemis, n.7, v.7, p.101-121, 2007.

SACHS, I.. Desenvolvimento includente, sustentável, sustentado. Rio de Janeiro: Garamond, 2004.

VIANA, V. M.. Meio Ambiente e Desenvolvimento Sustentável do Estado do Amazonas. Revista Eco 21, v.14, n.86, 2004

XAVIER G. K. R. S.; BRITO, A. P.; CASIMIRO, K. F.. A pesquisa no ensino fundamental: fonte para construção do conhecimento. Revista Educação Pública, 2009. 